\title{
Ghosts of Christmas past?: absence of trypanosomes in feral cats and black rats from Christmas Island and Western Australia
}

\author{
N. A. DYBING ${ }^{1}$, C. JACOBSON ${ }^{1,2}, \mathrm{P} \cdot \mathrm{IRWIN}^{1,2}, \mathrm{D} \cdot \mathrm{ALGAR}^{3}$ and P. J. ADAMS \\ ${ }^{1}$ School of Veterinary $\Xi^{\circ}$ Life Sciences, Murdoch University, Perth, Western Australia, Australia \\ ${ }^{2}$ Vector- and Water-Borne Pathogen Research Group, Murdoch University, Perth, Western Australia, Australia \\ ${ }^{3}$ Department of Parks and Wildlife, Science and Conservation, Perth, Western Australia, Australia
}

(Received 5 November 2015; revised 5 Fanuary 2016; accepted 27 fanuary 2016)

\section{S U M MAR Y}

Trypanosomes and Leishmania are vector-borne parasites associated with high morbidity and mortality. Trypanosoma lewisi, putatively introduced with black rats and fleas, has been implicated in the extinction of two native rodents on Christmas Island (CI) and native trypanosomes are hypothesized to have caused decline in Australian marsupial populations on the mainland. This study investigated the distribution and prevalence of Trypanosoma spp. and Leishmania spp. in two introduced pests (cats and black rats) for three Australian locations. Molecular screening (PCR) on spleen tissue was performed on cats from CI $(n=35)$, Dirk Hartog Island (DHI; $n=23)$ and southwest Western Australia ( and black rats from CI only $(n=46)$. Despite the continued presence of the intermediate and mechanical hosts of T. lewisi, there was no evidence of trypanosome or Leishmania infection in cats or rats from CI. Trypanosomes were not identified in cats from DHI or swWA. These findings suggest T. lewisi is no longer present on CI and endemic Trypanosoma spp. do not infect cats or rats in these locations.

Key words: Trypanosoma, Leishmania, Christmas Island, black rat, feral cat, Australia.

\section{INTRODUCTION}

Trypanosomes and Leishmania spp. are vectorborne parasites associated with severe disease in both animal and human hosts. The global distribution of Trypanosoma spp. and Leishmania spp. is heavily reliant on the presence of both reservoir hosts and competent vectors. Worldwide, cats (Felis catus) are reported to become infected by at least six Trypanosoma spp.; T. brucei, T. congolense, $T$. gambiense, T. cruzi, T. evansi and T. rangeli (Bowman et al. 2002). Likewise, 44 Trypanosoma spp. have been shown to infect rodents (Hoare, 1972; Milocco et al. 2013; Pumhom et al. 2015). Leishmania spp. are also zoonotic protozoan parasites (closely related both morphologically and genetically to Trypanosoma) that are usually transmitted by biting sand flies and are widely distributed through both tropical and temperate regions of the world. Leishmaniasis is also associated with high levels of morbidity and mortality (Svobodová et al. 2003; Gramiccia and Gradoni, 2005; Peacock, 2010). Over 40 mammal species are known to harbour Leishmania spp., including cats and rats, with the black, or 'ship' rat (Rattus rattus), increasingly recognized as an important natural reservoir in Leishmania transmission

* Corresponding author. School of Veterinary \& Life Sciences, Murdoch University, South Street, Western Australia 6150, Australia. E-mail: n.dybing@murdoch. edu.au
(Oliveira et al. 2005; Quinnell and Courtenay, 2009; Sherry et al. 2011). In Australia to date, eight novel Trypanosoma spp. have been identified in native wildlife (Paparini et al. 2011; Thompson et al. 2013, 2014), and leishmaniasis has been reported in macropods in the Northern Territory (Rose et al. 2004) and is thought to be transmitted by biting midges (Dougall et al. 2011). It is not known whether these endemic parasites can infect feline or rodent hosts.

On Christmas Island (CI), the extinction of two native rat species has been attributed to infection with Trypanosoma lewisi, thought to have been introduced with black rats during incursions by sea-faring traders during the late 19th century (Durham, 1908; Andrews, 1909). The observations of these early researchers appears to have been supported recently by Wyatt et al. (2008) who detected $T$. lewisi DNA in skin samples from two out of six $(33.3 \%)$ museum specimens of the now-extinct Maclear's rats (R. macleari), and one out of six (16.7\%) black rats collected by Durham at the time of European colonization of the island (Wyatt et al. 2008). More recently, speculation that trypanosomes were still present on CI was based on the observational finding of Trypanosoma/Leishmania-like organisms in a blood smear of a rat on the island (Hall et al. 2011). Additionally, Trypanosoma spp. infections have been implicated in the precipitous decline of the woylie (Bettongia penicillata) on mainland Western Australia (Smith et al. 2008; Averis 
et al. 2009), although the distribution and prevalence of trypanosome and Leishmania species in Western Australia is not well described.

As part of a larger research study into the effects of introduced species on wildlife in Australia and its islands, tissue samples from feral cats and black rats living on CI, Dirk Hartog Island (DHI) and in southwest Western Australia (swWA) were examined for the presence of Trypanosoma and Leishmania DNA. These locations represent areas of importance for wildlife conservation as well as for public health.

\section{METHODS}

\section{Study locations}

Samples were collected from three geographically and climatically distinct locations; from $\mathrm{CI}$, mainland swWA, and DHI. CI is an Australian Territory, located in the Indian Ocean $\left(10^{\circ} 29^{\prime} \mathrm{S}\right.$, $\left.105^{\circ} 38^{\prime} \mathrm{E}\right)$ approximately $360 \mathrm{~km}$ south of the Indonesian capital, Jakarta, with a tropical climate. The swWA is a large ecoregion, located south of a line from Geraldton $\left(28^{\circ} 46^{\prime} 28^{\prime \prime} \mathrm{S}, 114^{\circ} 36^{\prime} 32^{\prime \prime} \mathrm{E}\right)$ to Esperance $\left(33^{\circ} 51^{\prime} 40^{\prime \prime} \mathrm{S}, \quad 121^{\circ} 33^{\prime} 31^{\prime \prime} \mathrm{E}\right)$ with a Mediterranean climate. DHI is an arid inshore island $\left(25^{\circ} 50^{\prime} \mathrm{S}, 113^{\circ} 05^{\prime} \mathrm{E}\right)$ located to the west of Shark Bay off the Western Australian coast.

\section{Sample collection}

Cat cadavers were collected from CI ( $n=35 ; 8$ fresh and 27 frozen), DHI ( $n=23$; all frozen) and swWA $(n=58$; all frozen). Cats from CI and DHI were sourced from the Department of Parks and Wildlife (Parks and Wildlife) management programmes and cats from swWA were obtained during community-coordinated culling programs from 12 locations. Rats $(n=48 ; 23$ fresh and 25 frozen) were collected from CI concurrently with the cats. Spleen samples were collected at necropsy and preserved in 70\% ethanol.

\section{DNA extraction}

DNA was extracted from cat and rat spleen tissue using the Qiagen spin columns for blood and tissue kit according to the manufacturer's instructions (Qiagen, USA). Negative controls were used in the PCRs with the inclusion of PCR grade water in place of genomic DNA.

\section{PCR conditions - Trypanosoma}

The nested PCR protocol from Botero et al. (2013) was employed with generic Trypanosoma primers of the $18 \mathrm{~S}$ region which have been previously described (Maslov et al. 1996; McInnes et al. 2011). External primers used were SLF (5'-GC'T
TGT TTC AAG GAC TTA GC-3') and S762 (5'-GAC TTT TGC TTC CTC TAA TG-3') and internal primers were $\mathrm{S} 823 \mathrm{~F}$ (5'-CGA ACA AC'T GCC CTA TAC GC-3') and S662R (5'-GAC TAC AAT GGT CTC TAA TC-3'). Cultured Trypanosoma cruzi and T. lewisi were used as positive controls.

\section{PCR conditions - Leishmania}

Subsamples of spleens were tested for Leishmania spp. from CI samples only, feral cats $(n=10)$ and black rats $(n=45)$, with genus-specific primers adapted from Schönian et al. (2003). Primers were from the internal transcriber region (ITS1), OL1853 (5'-CTG GAT CAT TTT CCG ATG-3') and OL1854 (5'-TGA TAC CAC TTA TCG CAC TT-3').

A touchdown PCR was performed on all samples using $3 \mu \mathrm{L}$ of DNA (at $5 \mathrm{ng} \mu \mathrm{L}^{-1}$ ) in an $11.5 \mu \mathrm{L}$ reaction. The reaction contained $1 \times$ buffer, $3.0 \mathrm{~mm}$ $\mathrm{MgCl}, 0.5 \mathrm{~mm}$ dNTPs, $0.05 \mathrm{M}$ Betaine, $0.05 \mu \mathrm{L}$ Taq/Taq Gold and $10 \mu \mathrm{m}$ of each primer. PCR cycling conditions were optimized under the following conditions: 1 denaturation cycle at $94{ }^{\circ} \mathrm{C}$ for 5 $\min (\mathrm{Taq}) / 10 \mathrm{~min}$ (Taq Gold) followed by $94{ }^{\circ} \mathrm{C}$ for $20 \mathrm{~s}, 63-56^{\circ} \mathrm{C}$ for $60 \mathrm{~s}$ using $0.5^{\circ} \mathrm{C} \mathrm{cycle}^{-1}$ increments and $72{ }^{\circ} \mathrm{C}$ for $60 \mathrm{~s}$. This was then followed by 20 cycles of $94^{\circ} \mathrm{C}$ at $20 \mathrm{~s}, 56^{\circ} \mathrm{C}$ for $60 \mathrm{~s}, 72^{\circ} \mathrm{C}$ for $60 \mathrm{~s}$ and a final extension of $72^{\circ} \mathrm{C}$ for $5 \mathrm{~min}$ (Blackwell Laboratory, Australia). Positive controls included DNA extracted from Leishmania major, L. braziliensis, L. tropica, L. donovani and L. australiensis. All PCR products were run on a $1.5 \%$ agarose gel at $120 \mathrm{~V}$ for $1 \mathrm{~h}$ for visualization.

\section{Statistical analysis}

Confidence interval values were calculated using the exact binomial methods (Graat et al. 1997).

\section{RESULTS}

No Trypanosoma spp. were detected by PCR in any of the spleen samples (Table 1). Positive controls for $T$. cruzi and $T$. lewisi amplified at the correct product size and no amplification was detected within the negative control. Similarly, no Leishmania DNA was detected in either cat or rat spleen samples (Table 1). All Leishmania-positive controls produced amplified products at their corresponding sizes, whilst all negative controls did not produce amplification.

\section{DISCUSSION}

This study was conceived when the opportunity arose to sample cats and rats on $\mathrm{CI}$ after recent observations on pathology specimens suggested 
Table 1. Prevalence (\%) and 95\% confidence interval for Trypanosoma and Leishmania in cats and rats from three geographical regions.

\begin{tabular}{lllll}
\hline \hline & swWA & DHI & CI & \\
\cline { 2 - 5 } & F. catus & F. catus & F. catus & R. rattus \\
\hline Trypanosoma spp. & & & & \\
Samples $(n)$ & 58 & 23 & 35 & 48 \\
Positive samples $(n)$ & 0 & 0 & 0 & 0 \\
Prevalence 95\% confidence interval (\%) & $0.0,6.2$ & $0.0,14.8$ & $0.0,10.0$ & $0.0,7.4$ \\
Leishmania spp. & - & - & 10 & 43 \\
Samples $(n)$ & - & - & 0 & 0 \\
Positive samples $(n)$ & - & - & $0.0,30.8$ & $0.0,8.3$ \\
Prevalence 95\% confidence interval (\%) & & & & \\
\hline \hline
\end{tabular}

swWA, southwest Western Australia; DHI, Dirk Hartog Island; CI, Christmas Island.

that Trypanosoma spp. may persist in this confined habitat where historical records had putatively incriminated trypanosomiasis for the extinction of two native rodents. We were also interested to investigate whether Trypanosoma DNA could be detected in the blood of introduced animals in regions where trypanosomiasis appears to be endemic in native marsupials upon which they undoubtedly prey. However, we found no evidence of infection with Trypanosoma spp. in feral cats from three geographical locations or black rats on CI. Additionally, there was also no evidence of infection by Leishmania spp. in feral cats or black rats on CI. These results suggest that cats and rats are not currently acting as reservoirs for trypanosomes or Leishmania in these locations, and questions whether Trypanosoma infection persists in any form on CI.

The challenge presenting molecular research when pathogen DNA is not detected in any samples is to justify that target DNA was not missed due to inhibitors and/or suitability of the tissue for that particular work. We are confident that the samples used in this study yield viable DNA as these same samples were screened successfully for the presence of other blood-borne pathogens by molecular methods (e.g. Bartonella species; Dybing et al. (2016)), thus ruling out the presence of inhibitors.

Regarding the suitability of tissues used, the spleen is regarded as a reliable location for detecting numerous different blood-borne pathogens, including Trypanosoma, for reasons including; the spleen is the blood filtering organ so pathogens circulating in the blood would be expected to be present (Mebius and Kraal, 2005); sampling from the spleen was more sensitive than blood for detecting vector and blood-borne pathogens including trypanosome and ehrlichial infections (Albright and Albright, 1991; Harrus et al. 2004), and; the primers used in this study have been previously demonstrated/proven to detect trypanosomes in both blood and tissue samples (McInnes et al. 2011; Botero et al. 2013). The nested Trypanosoma PCR primers used in this study provide a highly sensitive methodology for detecting low DNA concentrations in tissues (McClatchey, 2002). Very low levels of DNA are highly likely to amplify when using nested PCR primers, compared to conventional single step PCR, as two primer pairs are required to amplify a target sequence and there is a decrease in non-specific banding (McClatchey, 2002; Pardo and Pérez-Villareal, 2004). Although the sensitivity of these primers has not been calculated for tissue, it has been calculated for blood (Dunlop et al. 2014). Given that Dunlop et al. (2014) calculated that use of these primers and amplification conditions in blood with $>74$ parasites $/ 0.3 \mathrm{~mL}$ had a detection sensitivity of $>80 \%$, it is extremely likely that even low levels of parasitaemia would be detected in spleen samples.

Whilst the possibility of missing the presence of either Trypanosoma or Leishmania occurring at very low levels of parasitaemia cannot be discounted, we do feel confident that the PCR protocol used would detect even low levels of parasitaemia in our samples. For the scope of this paper though, quantification of parasitaemia (intensity) was not considered as important as the presence/absence of Trypanosoma or Leishmania species.

Unfortunately serum samples were not available for rats or cats in this study; serological testing may have provided additional information regarding exposure (or otherwise) of the hosts to these parasites and should be considered for future investigations.

Whilst cat and rat spleen samples were sourced from a focal area on CI, specifically from around the town site, this was representative of the initial sampling area utilized by Durham (1908). Additionally, the relatively small size of this island $\left(135 \mathrm{~km}^{2}\right)$ suggests that Trypanosoma and Leishmania would have expected to have been identified in our samples if they were circulating within the rat and cat populations. Assuming a prevalence of at least $10 \%$, the probability of missing a positive animal is $0.006(0.6 \%)$ based on the sample size of 48 rats used in this study.

The only samples tested by Wyatt et al. (2008) from before black rat introductions to CI were 
from the bulldog rat ( $R$. nativitatis; $n=3)$, with PCR failing to detect any trypanosomes. Therefore it is not possible to confirm the presence or absence of $T$. lewisi on CI prior to black rat introduction (Wyatt et al. 2008). However, if T. lewisi was endemic on CI in the native Maclear's and bulldog rats before black rat introduction, then it could be hypothesized that it was similarly lost along with the demise of the native rats.

Based on the findings of this study, the link between black rats as the source of the Trypanosoma spp. on CI is tenuous considering the hypothesized host (black rats), intermediate host (Xenopsylla cheopis; Hoare (1972)) and a mechanical vector (Polyplax spinulosa; Khachoian and Arakelian (1978)) are still present on the island (unpublished results), whilst our efforts to detect the presence of any Trypanosoma spp. was not successful. If $T$. lewisi introduced with black rats has resulted in, or at least contributed to, the extinction of two endemic rodent species, then it would not be unreasonable to expect $T$. lewisi to still be present in these hosts today.

Whilst rodent (rat and mice) trypanosomes have been studied, there is still a paucity of information in Australia. Exotic trypanosomes found in native rodents include $T$. lewisi from the bush rat (25\%); a species genetically similar to $T$. lewisi in the ashgrey mouse $(50 \%)$; and an unknown Trypanosoma spp. in the Shark Bay mouse (16.7\%) (Averis et al. 2009). Introduced rodents infected with T. lewisi in Australia include the house mouse, brown rat and the black rat (Mackerras, 1959). Several novel Trypanosoma spp. have been identified in a range of Australian native wildlife species (Smith et al. 2008; Austen et al. 2009; Averis et al. 2009; Paparini et al. 2011). Indeed, Trypanosoma spp. have been implicated in the demise of marsupial populations in swWA (Smith et al. 2008; Averis et al. 2009).

In Australia, there is an absence of research into trypanosomes from cats however, natural and experimental infections of multiple species of Trypanosoma have been found in felines from other countries including; T. brucei, T. cruzi, T. evansi and $T$. rangeli. Experimental infections in cats have also been reported for $T$. congolense and $T$. gambiense. Trypanosoma cruzi is the most widely reported species occurring in cats with most cases originating from Latin America and prevalences ranging from 2.9 to $63.6 \%$ (Zeledón et al. 1975; Mott et al. 1978; Wisnivesky-Colli et al. 1985). However, many indigenous Australian mammal species are thought to be susceptible to infection by exotic Trypanosoma species if they were to establish in Australia (Thompson, 2013). The absence of trypanosome infection in cats sampled from swWA and DHI suggests that cats are not a major reservoir species in these areas and therefore may not contribute to trypanosome persistence in the environment.

Domestic cats and black rats have been identified as sources of infection of the pathogenic zoonosis caused by Leishmania infantum (Poli et al. 2002; Quinnell and Courtenay, 2009; Maia and Campino, 2011). At the time of this study a significant proportion of the CI population was transitory and originated from diverse geographic locations, including many areas where Leishmania is endemic. However, we found no evidence of feral cats or black rats acting as reservoirs for Leishmania spp. on CI.

\section{CONCLUSIONS}

This study found no evidence of Trypanosoma spp. infection in cats and black rats from three geographically distinct locations. Of particular interest is the absence of trypanosomes from black rats on CI given that $T$. lewisi has previously been reported as occurring in rats and other rodent hosts on the island, and has been hypothesized as contributing to the extinction of two endemic rodent species. Previous studies have implicated Trypanosoma spp. in fauna decline; however, in the case of CI, the findings of this study do not readily support this hypothesis. This study also found no evidence of feral cats or black rats harbouring Leishmania spp. on CI.

\section{ACKNOWLEDGEMENTS}

The authors would like to acknowledge Neil Hamilton from Parks and Wildlife and Michael Deller for sample collection from Dirk Hartog Island and Christmas Island as well as the farmers and the Red Card for Rabbits and Foxes programme for feral cat collection in the southwest WA. The authors would also like to acknowledge Adrian Wayne from Department of Parks and Wildlife for sample collection in the southwest WA. We would also like to thank the staff of Christmas Island National Parks for their assistance during this project providing a place to perform laboratory work. The Department of Immigration and Citizenship kindly provided accommodation during field collections. We appreciate the support received from Christmas Island Phosphates and would like to acknowledge support and encouragement from the community of Christmas Island and for allowing us to work around their properties. The authors would also like to acknowledge Chris Peacock and Ace Choo for guidance with the Leishmania analysis and Adriana Botero for guidance with the Trypanosoma analysis.

F I NA NCIAL SUPPORT

This work was completed as part of Narelle Dybing's PhD project with supporting funds provided by the Department of Parks and Wildlife (DPaW) as well as Murdoch University and the Murdoch University Veterinary Trust's Weston Fernie Research fund.

CONFLICT OF INTEREST

None. 


\section{ETHICAL STANDARDS}

The authors assert that all procedures contributing to this work comply with the ethical standards of the relevant national and institutional guides on the care and the use of laboratory animals.

\section{REFERENCES}

Albright, J. and Albright, J. (1991). Rodent trypanosomes: their conflict with the immune system of the host. Parasitology Today 7, 137-140.

Andrews, C. (1909). An account of Andrew's visit to Christmas Island in 1908. In Proceedings of the Zoological Society of London, Vol. 101.

Austen, J., Jefferies, R., Friend, J., Ryan, U., Adams, P. and Reid, S. (2009). Morphological and molecular characterization of Trypanosoma copemani n. sp. (Trypanosomatidae) isolated from Gilbert's potoroo (Potorous gilbertii) and quokka (Setonix brachyurus). Parasitology 136, 783-792.

Averis, S., Thompson, R., Lymbery, A., Wayne, A., Morris, K. and Smith, A. (2009). The diversity, distribution and host-parasite associations of trypanosomes in Western Australian wildlife. Parasitology 136, 1269-1279. Botero, A., Thompson, C. K., Peacock, C. S., Clode, P. L., Nicholls, P. K., Wayne, A. F., Lymbery, A. J. and Thompson, R. C. A. (2013). Trypanosomes genetic diversity, polyparasitism and the population decline of the critically endangered Australian marsupial, the brush tailed bettong or woylie (Bettongia penicillata). International fournal for Parasitology: Parasites and Wildlife 2, 77-89.

Bowman, D. D., Hendrix, C. M., Lindsay, D. S. and Barr, S. C. (2002). Feline Clinical Parasitology. Iowa Sate University Press, Ames.

Dougall, A. M., Alexander, B., Holt, D. C., Harris, T., Sultan, A. H., Bates, P. A., Rose, K. and Walton, S. F. (2011). Evidence incriminating midges (Diptera: Ceratopogonidae) as potential vectors of Leishmania in Australia. International fournal for Parasitology 41, 571-579.

Dunlop, J., Thompson, C. K., Godfrey, S. S. and Thompson, R. C. A. (2014). Sensitivity testing of trypanosome detection by PCR from whole blood samples using manual and automated DNA extraction methods. Experimental Parasitology 146, 20-24.

Durham, H. E. (1908). Notes on Nagana and on some Haematozoa observed during my travels. Parasitology 1, 227-235.

Dybing, N. A., Jacobson, C., Irwin, P., Algar, D. and Adams, P. J. (2016). Bartonella species identified in rodent and feline hosts from island and mainland Western Australia. Vector-Borne and Zoonotic Diseases 16, 238-244.

Graat, E. A. M., Frankena, K. and Bos, H. (1997). Principles and Methods of sampling in animal disease surveys. In Applications of Quantitative Methods in Veterinary Epidemiology (ed. Noodhuizen, J. P. T. M., Frankena, K., van der Hoofd, C. M. and Graat, E. A. M.), pp. 31-62. Wageningen Press, The Netherlands.

Gramiccia, M. and Gradoni, L. (2005). The current status of zoonotic leishmaniases and approaches to disease control. International fournal for Parasitology 35, 1169-1180

Hall, J., Rose, K., Spratt, D., Harlow, P., Donahoe, S., Andrew, P., Field, H., DeJong, C., Smith, C. and Hyatt, A. (2011). Assessment of Reptile and Mammal Disease Prevalence on Christmas Island. Report to Parks Australia. Australian Registry of Wildlife Health, Taronga Conservation Society Australia, Sydney, Australia.

Harrus, S., Kenny, M., Miara, L., Aizenberg, I., Waner, T. and Shaw, S. (2004). Comparison of simultaneous splenic sample PCR with blood sample PCR for diagnosis and treatment of experimental Ehrlichia canis infection. Antimicrobial Agents and Chemotherapy 48, 4488-4490.

Hoare, C. (1972). The Trypanosomes of Mammals. A Zoological Monograph. Blackwell Scientific Publications, Oxford, UK, p. 749.

Khachoian, V. and Arakelian, L. (1978). Case of the transmission of the rat trypanosome by lice. Parazitologiia 12, 451-453.

Mackerras, M. (1959). The haematozoa of Australian mammals. Australian Yournal of Zoology 7, 105-135.

Maia, C. and Campino, L. (2011). Can domestic cats be considered reservoir hosts of zoonotic leishmaniasis? Trends in Parasitology 27, 341-344. Maslov, D. A., Lukeš, J., Jirku, M. and Simpson, L. (1996). Phylogeny of trypanosomes as inferred from the small and large subunit rRNAs: implications for the evolution of parasitism in the trypanosomatid protozoa. Molecular and Biochemical Parasitology 75, 197-205.

McClatchey, K. D. (2002). Clinical Laboratory Medicine. Lippincott Williams \& Wilkins, Philadelphia.

McInnes, L. M., Hanger, J., Simmons, G., Reid, S. A. and Ryan, U. M. (2011). Novel trypanosome Trypanosoma gilletti sp. (Euglenozoa: Trypanosomatidae) and the extension of the host range of Trypanosoma copemani to include the koala (Phascolarctos cinereus). Parasitology 138, 59-70.
Mebius, R. E. and Kraal, G. (2005). Structure and function of the spleen. Nature Reviews Immunology 5, 606-616.

Milocco, C., Kamyingkird, K., Desquesnes, M., Jittapalapong, S., Herbreteau, V., Chaval, Y., Douangboupha, B. and Morand, S. (2013). Molecular demonstration of Trypanosoma evansi and Trypanosoma lewisi DNA in wild rodents from Cambodia, Lao PDR and Thailand. Transboundary and Emerging Diseases 60, 17-26.

Mott, K., Mota, E., Sherlock, I., Hoff, R., Muniz, T., Oliveira, T. and Draper, C. (1978). Trypanosoma cruzi infection in dogs and cats and household seroreactivity to $\mathrm{T}$. cruzi in a rural community in northeast Brazil. American Yournal of Tropical Medicine and Hygiene 27, 1123-1127. Oliveira, F. S., Pirmez, C., Pires, M. Q., Brazil, R. P. and Pacheco, R. S. (2005). PCR-based diagnosis for detection of Leishmania in skin and blood of rodents from an endemic area of cutaneous and visceral leishmaniasis in Brazil. Veterinary Parasitology 129, 219-227.

Paparini, A., Irwin, P. J., Warren, K., McInnes, L. M., de Tores, P. and Ryan, U. M. (2011). Identification of novel trypanosome genotypes in native Australian marsupials. Veterinary Parasitology 183, 21-30.

Pardo, M. A. and Pérez-Villareal, B. (2004). Identification of commercial canned tuna species by restriction site analysis of mitochondrial DNA products obtained by nested primer PCR. Food Chemistry 86, 143-150.

Peacock, C. (2010). Host and parasite genomics, an Australasian perspective. Parasite Immunology 32, 599-606.

Poli, A., Abramo, F., Barsotti, P., Leva, S., Gramiccia, M., Ludovisi, A. and Mancianti, F. (2002). Feline leishmaniosis due to Leishmania infantum in Italy. Veterinary Parasitology 106, 181-191.

Pumhom, P., Morand, S., Tran, A., Jittapalapong, S. and Desquesnes, M. (2015). Trypanosoma from rodents as potential source of infection in human-shaped landscapes of South-East Asia. Veterinary Parasitology 208, 174-180.

Quinnel1, R. J. and Courtenay, O. (2009). Transmission, reservoir hosts and control of zoonotic visceral leishmaniasis. Parasitology 136(Special Issue 14), 1915-1934.

Rose, K., Curtis, J., Baldwin, T., Mathis, A., Kumar, B., Sakthianandeswaren, A., Spurck, T., Low Choy, J. and Handman, E. (2004). Cutaneous leishmaniasis in red kangaroos: isolation and characterisation of the causative organisms. International Yournal for Parasitology 34, 655-664.

Schönian, G., Nasereddin, A., Dinse, N., Schweynoch, C., Schallig, H. D. F. H., Presber, W. and Jaffe, C. L. (2003). PCR diagnosis and characterization of Leishmania in local and imported clinical samples. Diagnostic Microbiology and Infectious Disease 47, 349-358.

Sherry, K., Espinosa, C., Furlanello, T., Miranda, C., Miro, G., Montoya, A., Ribas, F., Solano-Gallego, L. and Trotta, M. (2011). A serological and molecular study of Leishmania infantum infection in cats from the Island of Ibiza (Spain). Vector-Borne and Zoonotic Diseases 11,239

Smith, A., Clark, P., Averis, S., Lymbery, A., Wayne, A., Morris, K. and Thompson, R. (2008). Trypanosomes in a declining species of threatened Australian marsupial, the brush-tailed bettong Bettongia penicillata (Marsupialia: Potoroidae). Parasitology 135, 1329-1335.

Svobodová, M., Votýpka, J., Nicolas, L. and Volf, P. (2003). Leishmania tropica in the black rat (Rattus rattus): persistence and transmission from asymptomatic host to sand fly vector Phlebotomus sergenti. Microbes and Infection 5, 361-364

Thompson, C. K., Botero, A., Wayne, A. F., Godfrey, S. S., Lymbery, A. J. and Thompson, R. A. (2013). Morphological polymorphism of Trypanosoma copemani and description of the genetically diverse $T$. vegrandis $\mathrm{sp}$. nov. from the critically endangered Australian potoroid, the brush-tailed bettong (Bettongia penicillata (Gray, 1837)). Parasites and Vectors 6, 121.

Thompson, C. K., Godfrey, S. S. and Thompson, R. (2014). Trypanosomes of Australian mammals: a review. International Yournal for Parasitology: Parasites and Wildlife 3, 57-66.

Thompson, R. A. (2013). Parasite zoonoses and wildlife: one health, spillover and human activity. International fournal for Parasitology 43, 1079-1088. Wisnivesky-Colli, C., Gürtler, R. E., Solarz, N. D., Lauricella, M. A. and Segura, E. L. (1985). Epidemiological role of humans, dogs and cats in the transmission of Trypanosoma cruzi in a central area of Argentina. Revista do Instituto de Medicina Tropical 27, 346-352.

Wyatt, K. B., Campos, P. F., Gilbert, M. T. P., Kolokotronis, S.-O., Hynes, W. H., DeSalle, R., Daszak, P., MacPhee, R. D. E. and Greenwood, A. D. (2008). Historical mammal extinction on Christmas Island (Indian Ocean) correlates with introduced infectious disease. PLoS ONE 3, e3602.

Zeledón, R., Solano, G., Burstin, L. and Swartzwelder, J. (1975). Epidemiological pattern of Chagas' disease in an endemic area of Costa Rica. American Yournal of Tropical Medicine and Hygiene 24, 214-225. 